\title{
TCOM \\ Science live - articulating the aims and ethos of science event practitioners in the U.S.A. and U.K.
}

\section{Laura Fogg-Rogers, Ben Weihe, Dane Comerford, Julie Fooshee and John Durant}

\begin{abstract}
Live science events engage publics with science in a social context. This article articulates the aims and ethos of this growing sector within a research context. Semi-structured interviews $(\mathrm{N}=13)$ and focus groups $(\mathrm{N}=77)$ were conducted with event practitioners (both professional and volunteers) in the U.S.A. and U.K.. Inductive thematic analysis indicated that event producers aim to raise awareness of and professionalism in the sector. In particular, they seek to develop research into long-term impacts of events for both audiences and practitioners.
\end{abstract}

Keywords

Informal learning; Professionalism, professional development and training in science communication; Public engagement with science and technology

DOI

https://doi.org/10.22323/2.18040801

Submitted: 5th June 2019

Accepted: 16th August 2019

Published: 9th September 2019

Context

Live events are characterised by their time-bound, physical presence, and create enjoyable moments from these special features [Durant, 2012]. The science events sector encompasses a wide diversity of forms: stage shows, storytelling,

performing arts; science cafes and other dialogue events; science festivals and other massively collaborative events; initiatives that incorporate science activity into non-science events; science busking and similar street level interventions; and much other activity, some of which purposely defies categorization [Weihe, 2014]. For most of this sector, science is taken as an inclusive term, bringing together all areas of Science, Technology, Engineering and Mathematics (STEM), and even including the Arts (STEAM) or other social sciences and humanities.

To explore the development of such events and establish a distinct professional sector, a transatlantic research project, Science Live, aimed to research the practice of live public science events. The project brought together practitioners and external supporters of live science events from the United States of America (U.S.A.) and the United Kingdom (U.K.). As an action research project, it aimed to widen participation in such activity whilst also exploring its impact. A broad 
constituency of people, including volunteers running community events through to professional marketeers producing paid-for international festivals, have created a synthesis of common aspirations for a sector driven by a wide variety of individual aims. This practice insight is a result of this collaboration, and is the first time the science events sector has articulated its own aims and ethos in a research context.

Much of what is known about live science events has been captured in literature describing science festivals, and to some degree can be seen as reflective of the wider live public science events sector [Bultitude, McDonald and Custead, 2011; Fogg-Rogers et al., 2015]. Festival events have been described in the event management literature as time-bound, themed public celebrations [Getz, 2010], and are well researched for their abilities to increase local and regional tourism through focused marketing [Daniel, Bogdan and Daniel, 2012; Getz, 2008; Kim et al., 2010]. In a survey of EU science communication events, the most widely shared objective of science festivals was to 'raise public awareness of science' [Fikus, 2005]. However, festivals have been criticized for failing to reach beyond the 'already engaged' [Bultitude, 2014] — audiences who are already scientifically literate and interested in science. While science festival research is relevant to many science events, the science events sector taken as a whole does not have the active practitioner networks that support festivals, such as the Science Festival Alliance in the U.S.A. [Science Festival Alliance, 2013] and the Science Festivals Network in the U.K. [British Science Association, 2018].

Evaluations of science festivals have found that visitors' self-reported benefits of attendance are related to non-formal learning about science and scientific research [Fogg-Rogers et al., 2015; Jensen and Buckley, 2011; Science Festival Alliance, 2013]. Practitioners emphasize that live events are fundamentally social experiences, which suggests that identity affirmation and/or social transformation is an outcome inherent to live engagement activity [Durant et al., 2016]. Learning in these contexts is not confined to acquiring factual knowledge; it is generally understood to encompass knowledge and understanding; skills; attitudes, opinions and beliefs; creativity, inspiration and enjoyment; and action and progression [Museums Libraries and Archives Council, 2014]. Indeed, interaction with scientists themselves has been identified as one of the key learning and social experiences from live events [Boyette and Ramsey, 2019]. We can presume that the distinct characteristics of live science events enable scientific literacy and science capital by developing informed decision-making skills [Liu, 2009], enhancing social connections to science [Archer et al., 2015], or driving participation in science-related issues and activities throughout life as scientifically literate citizens [Crowell and Schunn, 2014].

Events within universities, learned institutions, museums and science centers facilitate learning alongside wider organizational aims of public relations and public engagement [Grand et al., 2015; Weihe, 2014]. Many science events run by non-institutional groups and charities also aim to link science with society through wider cultural contexts, such as theatre, art, and comedy, or via creative community-based collaboration [Dowell, 2014]. Long-term evidence for the impacts and effectiveness of these aims is generally limited [Wellcome Trust, 2012] and could be a fruitful area of future research. 
Audiences and practitioners assert the value of live science events, but there is little overall tracking of or advocacy for such activity. Event practitioners are often not aware of each other's efforts [Lloyd et al., 2012]. Practice is rarely evaluated systematically or across different forms, and when it is, there is no straightforward way to share findings with the full range of event practitioners. Rapid innovations in practice have outpaced both research into the impacts of events and knowledge of what will best support the involvement of a diverse base of practitioners. Finally, external supporters of events, including funders and administrators, may be better equipped to realize their own institutional goals with a clearer set of facts and requirements that build into a coherent narrative explaining the role that live events play in the informal science learning ecosystem.

This landscape study aimed to qualitatively explore the perceptions and views of practitioners in the developing field of live science events. The aims of the study were to:

- Articulate common threads that define the sector and establish a shared terminology

- Summarise the existing activity related to events

- Prioritise potentially fruitful areas for future investigation

People who organize live science events in the U.K. or U.S.A. were purposively recruited to the project in 2015, with subsequent snowball sampling aiming to generate a cross-sectional sample of event producers. Ethics consent was received from the University of the West of England Research Ethics Committee in the U.K. and the Massachusetts Institute of Technology Institutional Review Board in the United States of America (U.S.A.). All participants received appropriate Participant Information Sheets and signed consent forms. Participation was voluntary, with data grouped and anonymized for reporting.

\section{Open discussion workshops}

Consultations with practitioners began with two open discussion workshops, first in the U.K. then followed by the U.S.A. Open invitations to attend were sent to website mailing lists, social media, and relevant science communication organizations.

The U.K. workshop was held in Cambridge (U.K.) and attracted 55 attendees, consisting of both academics and practitioners in the field. The workshop included a day-and-a-half of discussion, and was timed so that attendees could also participate in a regular U.K. Science Festival Network meeting and attend Cambridge Science Festival events. A short landscape study questionnaire was discussed at this meeting but was rejected by participants in favor of qualitative methodologies.

The U.S.A. workshop was held in Cambridge (U.S.A.) and attracted 56 attendees, consisting of both academics and practitioners in the field. This day-long workshop 
was timed so that attendees could also participate in the International Public Science Events Conference.

\section{Interviews and focus groups}

The development of and subsequent use of semi-structured interview protocols sought community-relevant themes and specific issues for further interrogation; questions were adapted for use in individual interviews or collective focus groups. Core questions and optional interviewer prompts were discussed and ratified by the Science Live project team, with resultant protocols used by all project team members for consistency.

Table 1. Characteristics of the interviewees in the Science Live project.

\begin{tabular}{|c|c|c|c|c|}
\hline Participant & & Position & Organisation type & Gender \\
\hline $\begin{array}{l}\text { Interviewee } \\
\text { (Inv1) }\end{array}$ & 1 & $\begin{array}{l}\text { Organiser and } \\
\text { academic }\end{array}$ & Voluntary events & Female \\
\hline $\begin{array}{l}\text { Interviewee } \\
\text { (Inv2) }\end{array}$ & 2 & Manager & Arts events & Male \\
\hline $\begin{array}{l}\text { Interviewee } \\
\text { (Inv3) }\end{array}$ & 3 & Organiser & Voluntary events & Male \\
\hline $\begin{array}{l}\text { Interviewee } \\
\text { (Inv4) }\end{array}$ & 4 & Manager & Learned institution events & Female \\
\hline $\begin{array}{l}\text { Interviewee } \\
\text { (Inv5) }\end{array}$ & 5 & Manager & Arts events & Female \\
\hline $\begin{array}{l}\text { Interviewee } \\
\text { (Inv6) }\end{array}$ & 6 & Manager & University events & Male \\
\hline $\begin{array}{l}\text { Interviewee } \\
\text { (Inv7) }\end{array}$ & 7 & Manager & University events & Male \\
\hline $\begin{array}{l}\text { Interviewee } \\
\text { (Inv8) }\end{array}$ & 8 & Manager & Science festival events & Female \\
\hline $\begin{array}{l}\text { Interviewee } \\
\text { (Inv9) }\end{array}$ & 9 & Manager & Learned institution events & Male \\
\hline $\begin{array}{l}\text { Interviewee } \\
\text { (Inv10) }\end{array}$ & 10 & Manager & University events & Female \\
\hline $\begin{array}{l}\text { Interviewee } \\
\text { (Inv11) }\end{array}$ & 11 & Manager & Arts events & Male \\
\hline $\begin{array}{l}\text { Interviewee } \\
\text { (Inv12) }\end{array}$ & 12 & Manager & University events & Female \\
\hline $\begin{array}{l}\text { Interviewee } \\
\text { (Inv13) }\end{array}$ & 13 & Manager & Arts events & Male \\
\hline
\end{tabular}

Practitioners (including STEAM academics) in science communication were purposively recruited. Three data capture methods were used in the U.K.: 18 practitioners (open invitation) took part in one of two face-to-face semi-structured focus groups; 16 performers and science show communicators (invited) took part in one of two focus groups either face-to-face or via video conferencing; and 13 practitioners consented to take part in semi-structured interviews either face-to-face or over the telephone. In the U.S.A., 43 practitioners (invited and open recruitment) took part in six face-to-face semi-structured focus groups. Participant 
characteristics for the interviews are described in Table 1 and for the focus groups in Table 2.

Table 2. Characteristics of the focus groups in the Science Live project.

\begin{tabular}{|c|c|c|c|c|}
\hline $\begin{array}{l}\text { Focus } \\
\text { group }\end{array}$ & $\begin{array}{l}\text { Number of } \\
\text { participants }\end{array}$ & Country & $\begin{array}{l}\text { Gender ratio } \\
\text { (Male:Female) }\end{array}$ & Type of group \\
\hline A & 8 & U.K. & $6: 2$ & $\begin{array}{l}\text { Science communication show } \\
\text { performers }\end{array}$ \\
\hline B & 8 & U.K. & $2: 6$ & $\begin{array}{l}\text { Science communication show } \\
\text { organisers and performers }\end{array}$ \\
\hline C & 8 & U.K. & $2: 6$ & $\begin{array}{l}\text { Science event organisers and } \\
\text { academics }\end{array}$ \\
\hline $\mathrm{D}$ & 10 & U.K. & $5: 5$ & $\begin{array}{l}\text { Science event organisers and } \\
\text { academics }\end{array}$ \\
\hline $\mathrm{E}$ & 9 & U.S.A. & $1: 8$ & Science event organisers \\
\hline $\mathrm{F}$ & 7 & U.S.A. & $1: 6$ & Science event organisers \\
\hline G & 5 & U.S.A. & $1: 4$ & Science event organisers \\
\hline $\mathrm{H}$ & 7 & U.S.A. & $2: 5$ & Science event organisers \\
\hline I & 8 & U.S.A. & $0: 8$ & Science event organisers \\
\hline $\mathrm{J}$ & 7 & U.S.A. & $2: 5$ & Science event organisers \\
\hline
\end{tabular}

In total, 13 participants took part in semi-structured interviews, and 77 participants took part in semi-structured focus groups. All interviews were audio recorded and then transcribed verbatim by professional transcription services. The transcripts were analyzed using the thematic analysis method to develop inductive themes [Braun and Clarke, 2006]. Data from the interviews and the U.K. and U.S.A. focus groups were triangulated into one coding frame; a process of intra-coder constant comparison then enabled the further development of one thematic hierarchy [Thomas, 2006].

\section{Practitioner ratification}

Interim findings from the thematic analysis were ratified by practitioners in the field at two national U.K. conferences. Practitioners at the U.K. Science Communication Conference (June 18, 2015) were invited to give feedback on the project progress and methodologies used; 8 practitioners responded to the open call. Practitioners at the U.K. British Interactive Group (BIG) Conference (July 23, 2015) were also invited to learn about the project methodologies and to give feedback on the interim findings; 25 practitioners responded to the open call.

Results and discussion
Results from the project are presented here under the relevant section headings. In total, the project consulted with 136 practitioners at the open discussion workshops and conference sessions in both the U.S.A. and U.K.. Qualitative data from 90 participants in the interviews and focus groups from both the U.S.A. and U.K. is integrated here, as well as overall feedback from the open discussion workshops and conference feedback. 


\section{Drawing a (porous) line in the sand}

Participants in the interviews and focus groups were asked how they would describe a live public science event, along with which types of events they would classify as meeting their definition. Consensus was reached by almost all interviewees that live public science events did constitute a distinct sector, which was not currently adequately represented by other professional groups or organizations. While much debate was instigated about the types of events which constituted this sector, overall, participants felt that live public science events shared many common features and practitioners could learn much from each other. Analysis of this data has led to the following description:

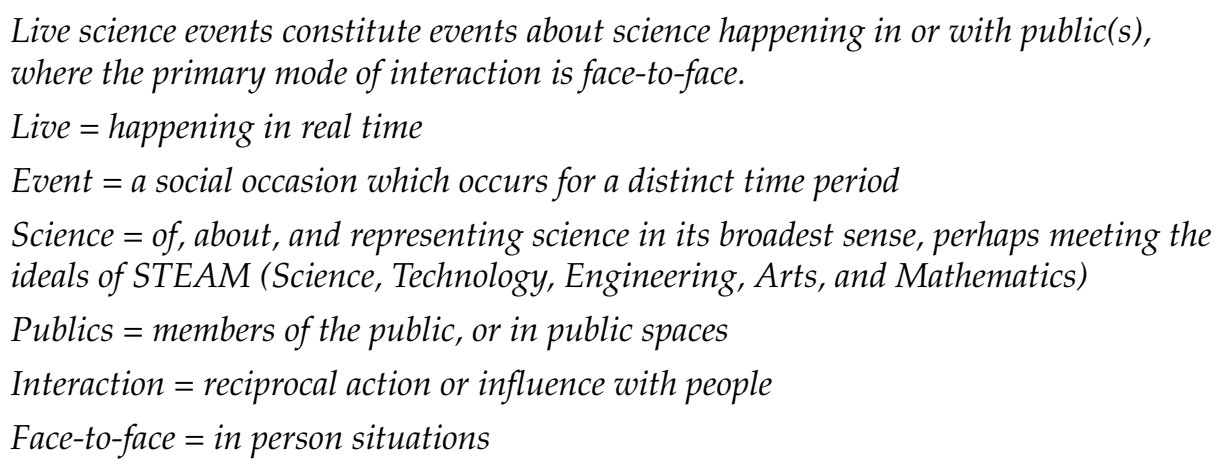

This consensus was found within the individual interviews but also between participants in focus groups in the U.K. and U.S.A.; as well as at the BIG U.K. conference where $76 \%$ (total $N=25$ ) of participants voted that they 'liked' or 'strongly liked' the description, and this was reinforced by qualitative data.

Inv2 - We're just, we're all in it together, trying to inspire people about science and depending on which camp you sit in, whether you think comedy is the best live experience or a night at the Globe or sitting in a lecture hall, I just feel like they're all very internally connected...

Inv1 - There are things we have in common, we want to know about the venues, we want to know about the people. So I think you can identify hot spots, if you like, of interest.

However, many participants were keen to stress that a distinguishing feature of the sector was its creativity and originality, and it was felt that a rigid definition would constrain these qualities.

Focus group B participant - There's always a danger when you define a sector because you automatically exclude people. So we exclude something which we didn't think about or didn't know that they existed or they don't exist yet, and then they're outside the circle.

Inv1 - I think there's a kind of loose boundary that you can throw around all these things but it's immensely porous, and should be porous, because what this, the live sector, is all about is innovation, and change. And the instant you start constraining and putting a tight boundary; for me, you reduce the possibility of innovation and change.

The wide variety of events and example quotes illustrating them can be seen in Table 3. 
Table 3. Examples of live public science event styles.

\begin{tabular}{|c|c|}
\hline Event category & Example descriptive quote taken from participant interviews and focus groups \\
\hline Science festival & $\begin{array}{l}\text { "For the established audiences, the fact that there is a festival I think is the important thing there. The } \\
\text { fact we have a coordinated, coherent science festival [defined as a single program covering multiple } \\
\text { events, days, venues and events partners], with the related marketing that goes on for that, means } \\
\text { that people will come to those events and people pay for those events as well". }\end{array}$ \\
\hline $\begin{array}{l}\text { Segment in a general } \\
\text { (art/music/lifestyle) } \\
\text { festival }\end{array}$ & $\begin{array}{l}\text { "We are engaging with audiences who are not primarily motivated by an interest in science, they } \\
\text { may not have any interest in science. And so we are competing with other arts events, music, popular } \\
\text { music, comedy, all sorts of other things that are going on that are prioritising entertainment, and } \\
\text { wider cultural experiences. We've always focussed on a very playful approach to engaging people } \\
\text { with science [which] engages with this fusion of both arts and science and creativity". }\end{array}$ \\
\hline Science café & $\begin{array}{l}\text { "The kind of ethos is to be a place where people can come and have a conversation that just happens } \\
\text { to be about science, instead of football or soap operas, or whatever. You know, if you just turn to the } \\
\text { person next to you and say, "I haven't a clue what she's talking about", that's an engagement with } \\
\text { the topic". }\end{array}$ \\
\hline Dialogue discussions & $\begin{array}{l}\text { "I think there is a very strong case for communicative engagement which recognises the expertise of } \\
\text { other audiences. I guess there's a difference between engaging with science and engaging with the } \\
\text { implications of science or the future of what science could mean for society. So, you know, it's one } \\
\text { thing being fascinated about how electrons move through photosystems. It's another thing thinking } \\
\text { about what we think science is for and what we want it to do for society and what the right policy } \\
\text { response is". }\end{array}$ \\
\hline $\begin{array}{l}\text { Events at museums } \\
\text { and science centers }\end{array}$ & $\begin{array}{l}\text { "[We hold] family science days, which is something like a science festival but it happens in our } \\
\text { exhibit hall, because one of our primary audiences is scientists, and wanting not just to train them } \\
\text { to do public engagement, but to encourage them to do public engagement and help them see what } \\
\text { it looks like. We keep the day free for participants so that it's easy to get to, and we even provide } \\
\text { transportation funding for some groups, to come and participate". }\end{array}$ \\
\hline $\begin{array}{l}\text { Events at universit- } \\
\text { ies or learned institu- } \\
\text { tions }\end{array}$ & $\begin{array}{l}\text { "[Our aims are to] celebrate and raise awareness of science in [our city], and getting our research } \\
\text { and our academics to get their research out to other audiences under the public engagement with } \\
\text { research banner... It's giving easy routes for our academics and younger researchers to start talking } \\
\text { about their research to other audiences, so then they become more comfortable talking to general } \\
\text { public audiences about what they do, and they're better at talking to politicians and policymakers and } \\
\text { businesses". }\end{array}$ \\
\hline $\begin{array}{l}\text { Outreach events in or } \\
\text { for schools }\end{array}$ & $\begin{array}{l}\text { "[We aim] to inspire more people to get into physics and engineering at secondary level and for } \\
\text { careers... Sometimes there might be an explicit learning goal so it might be that there's a particular } \\
\text { bit of the curriculum that [we need] to communicate. But more broadly, as a general aim to encourage } \\
\text { interest and enthusiasm for science and engineering and to reinforce that as part of the culture, and } \\
\text { science literacy". }\end{array}$ \\
\hline $\begin{array}{l}\text { Science art/theatre } \\
\text { events }\end{array}$ & $\begin{array}{l}\text { "Theatre is a deeply emotional experience; like it's a guide book to the past, it's a mirror to now, it's a } \\
\text { portal to the future. Our aim is to use the very potent set of variables that come with what a theatre } \\
\text { play or experience is and that's a mode of expression that can take something that's seemingly very } \\
\text { complicated and put that into three dimensions, and along the way you kind of create a world view". }\end{array}$ \\
\hline Science busking & $\begin{array}{l}\text { "I think that the diversity has gone up and from my experience there are two drivers for that. One is } \\
\text { accessibility, in that many people who are devising and delivering live science events are interested } \\
\text { in reaching audiences which wouldn't typically choose to come to those events. And the second one, } \\
\text { which is probably not a particularly popular thing to say, but I think it is driven by where the funding } \\
\text { is coming from. And there is a lot of funding that would have funded more traditional science fairs or } \\
\text { talks, that now you can't get unless you do something a bit off the wall or you're collaborating with a } \\
\text { different field or a completely different discipline". }\end{array}$ \\
\hline $\begin{array}{l}\text { Science comedy or } \\
\text { pub events }\end{array}$ & $\begin{array}{l}\text { "What we do are science comedy shows that are very definitely theatre [performance] shows and they } \\
\text { are definitely for adults, which is what puts us aside from many other events. The other thing that } \\
\text { puts us aside is that we're completely self-funded, we do not get any grants or anything like that; we } \\
\text { are completely reliant on ticket sales". }\end{array}$ \\
\hline
\end{tabular}

Warm bodies seeing eye to eye

All participants indicated that live events were time- and space-bound; stimulating energy and excitement about a topic within a defined period of time, albeit with 
longer-term effects that are difficult to measure. Participants therefore agreed that exhibits or interactive activities which remained in place for months or longer, such as at science centers, could not be considered as events. Many were keen to point out however that events could be created around these exhibits or activities to generate further interest. One interesting area of conflict was generated around the length of the period of time constituting an event or an experience: some people felt that free-flow engagement interventions, such as street performances or other non-participatory activities were not an event, as people were not intending to come to the activity and did not stay for a set amount of time.

\begin{abstract}
Focus group B participant - I'm not sure I'd call science busking an event because people come and go. So there's not a start and finish time. There are the people who come or move along, you know, it's like, it's an intervention and an experience certainly, but is it an event?

Focus group D participant - Maybe it's important that we'd made a conscious decision to go to it. You have to have opted to walk through the door for some reason. Perhaps you need to make a conscious decision to go there for it to be an event.
\end{abstract}

A major point of discussion amongst interviewees and focus group participants was also about the nature of face-to-face or online interactions. Both types of interactions were included in the initial description of live public science events, but participants overwhelmingly felt that the primary mode of interaction needed to be face-to-face, in order to generate a social context. Virtual reality or avatar-based online experiences were not extensively discussed and sentiment towards digital engagement may change over time.
Focus group D participant - I would prefer it if they were categorized separately [online and face-to-face], like seeing warm bodies and the whites of each other's eyes basically, but so the person speaking seeing their audience as well as the audience seeing.
Focus group B participant - [I believe that] we all think that it's a social experience as well, so it's not just about you being live in the room, it's about multiple people being there together. And I think something different happens when you're in a room with social connections. That's what makes it essentially more engaging and memorable. It's because you're experiencing it with other people and the fact that the dynamics is important.

However, participants still felt online interactions had value, and offered something extra or different to a physical event including a wider reach with no geographical boundaries. Many wondered if concepts of interaction were in fact generational, and that younger people would be as satisfied with an online interaction as they would be in person.

Focus group I participant - I'm old-fashioned I guess in this and so maybe it's an old person's perspective versus a young person's perspective. So for a young person that maybe 'live'; to me that's not 'live'. 'Live' is really - I can touch, feel, see the person, so I'm not convinced that is 'live'. It's a different class, it's a separate category.

Interactive online events like 'I'm a Scientist, Get Me Out of Here' [Pontin, 2011] were raised as a special case. Some participants argued that this sort of event should be included in the sector. 
Inv10 - I mean, 'I'm a Scientist, Get Me Out of Here' ... I think now that technology is opening up a whole different means to do engagement. Just as much as speaking to someone through the different means of communication is live; it doesn't necessarily need to be face to face.

\section{Science engagement as part of wider culture}

Within both online and face-to-face styles of events, interaction between audiences, and between audiences and scientists, was identified as a key element of live public science events. Participants discussed the opportunity to interact with others in the room or online space, and the occasions created to question and discuss science and its implications. They felt that this was a special feature of live public science events which was not offered by other science communication sectors.

Inv4 - So those connections that people make between one another but also between the experts that we bring to that public platform; I think that's one of the most special things that we can do because those connections go further than the memories of an event might go.

Some participants indicated that the interaction needed to be between scientists and the audience, rather than with science communicators. Whilst they acknowledged the value of social interaction, they felt that live public science events needed to include genuine STEM researchers in order to be authentic. Many of these participants came from university sectors which are addressing 'Public Engagement with Science' ideals [Bensaude Vincent, 2014; Palmer and Schibeci, 2012] however, other research has reinforced that audiences value direct interactions with scientists at science festivals [Boyette and Ramsey, 2019; Fogg-Rogers et al., 2015; Jensen and Buckley, 2014]

Focus group H participant - I come down on the side [that] if there is not a scientist involved, it's great science communication, but maybe it's not public engagement with science.

Focus group I participant - The interactions with the scientists get rated so high that it's an opportunity to break down that wall between what we think a scientist does and what they actually do.

However, participants who were performers or producers indicated that they thought there was an added value to events which were professionally produced. They described how these shows or activities created memorable, emotional experiences, which consequently may enable more learning to take place [Dierking, 2008].

Focus group C participant - [Professional communicators] are absolutely specialist in capturing people's attention; much more so than somebody who's spent their life doing research. So they've got those skills that they can offer this sort of thing.

Focus group A participant - The larger the show is, the more exciting it ends up being. It's easier to whip up a large audience into frenzy; for them to feel they've had an extraordinarily exciting time. 
The fun, creative, and informal nature of live public science events was highlighted by participants as a defining feature of the sector. As events are often marketed as part of the general cultural calendar, many participants argued that live public science events therefore have a unique ability to connect science to society. This was particularly important where events attempted to integrate science into wider cultural offerings, perhaps to reach people who may not ordinarily be interested in science.

Focus group F participant - I think what science events offer as a sector, is an interface with different elements of culture in a different capacity.

Focus group J participant - I think there's this sense you don't necessarily have to hit people over the head with it, especially if it's not purely about information delivery, but it's got other underlying drivers like reaching wider audiences, engagement and participation - the acceptance of science as part of culture.

In order to enact this cultural approach to science communication, participants argued that creating the right atmosphere was particularly important. Participants in this research stressed that venue choice and atmosphere were critical to enable audiences to feel relaxed enough to engage with a subject which they did not necessarily feel traditionally comfortable with.

\begin{abstract}
Inv11 - Our ethos has always been we want to create a party relaxed atmosphere. Because you know what it's like, if you go to a party, the best ideas are the ones you have there, because you're relaxed, you're more open to new ideas, you're more open to stimulation. [This] then means that people are much more open to hearing things and being challenged about their preconceptions and debating things and moving those conversations forward.

Focus group G participant - We're just smack dab in the middle of [a carnival] and we've got this great photo of all these women in their costumes shooting off rockets. They love it because they're in an environment where they're really comfortable, where they choose to go, and so there's more of an openness than if they're dragged to a science place and they're a non-science person.
\end{abstract}

\title{
Evaluation is mandated, but academic literature is practically irrelevant
}

Many participants stated that connections to science communication research are not a principal focus of their work, and as such there is a predisposition toward short-term evaluations. Many practitioners are more interested in seeing examples of deployment and how this could fit with their own programs. However, almost every practitioner described undertaking some evaluation of their work as this was driven by funding requirements. The methodologies used were established social science research methods (questionnaires, interviews, focus groups, snapshot opinions etc.), and were mostly undertaken by the practitioners themselves. Larger events or funded projects were also able to pay for external organizations to evaluate their work. Many reported that their evaluations were useful to learn more about their audiences and which aspects of their project worked well. However, many practitioners did not feel confident in their abilities to robustly evaluate events, and therefore to trust the results that they and others made public. 
Focus group H participant - We do a lot of evaluation; it's mandated by our funders. I don't really think of the evaluation as being particularly useful in telling you anything truthful. I do it more as market research and [it takes a lot] for me to actually trust anything that comes out of an event festival.

Focus group D participant - Evaluation-wise, it's very focused on how's the event gone and how have our audience enjoyed it, and what should we change for next year. I would like it to be more about has it changed perceptions and influenced people, and are they doing things differently as a result of coming to the event. But convincing the funders that is valuable is not very easy, because they're more interested in how many people came to your event and that's seen as the measure of success, which it's not.

Despite most participants undertaking some evaluation work, many admitted to not routinely reading other practitioners' evaluation reports. Participants who were responsible for applying for funding indicated that they referenced reports when they needed to write funding proposals, but otherwise this was not their main priority. This was especially true of academic literature, which many practitioners described as impenetrable and irrelevant to practice. Some questioned whether the culture of evaluation was actually benefitting the sector's development, or simply aiding with gaining more funding.

Inv9 - I mean the academic literature is often useless [laughs]. If I'm honest, it's hard to find time to be able to engage with it, both academic published literature and more evaluations like ours.

Inv3 - I worry about discussion of evaluation methods without any discussion of aims. I think there should be a rethink right across the sector of what events are actually for... because the temptation is to be slightly cynical and say the evaluation is to better prove how good I am, so that I can get more funding. Whereas the evaluation ought to be about me finding out whether I achieve what I wanted to achieve.

Indeed, practitioners who were volunteers or freelancers did not tend to evaluate their events, as they were more driven by ensuring that people returned to their events or performances. Notwithstanding these reservations, practitioners and academics were supportive of further developing evidence-based practice for live public science events, keen to share their existing knowledge of organizing events and advancing the sector through focused research in partnership with academics. However, significant barriers were raised about how these ideas could be developed practically. For all practitioners, the main barrier was time - possibly reduced to legitimacy and resource - as they felt that reading about other people's event evaluations and academic research would prevent them from doing their main job of producing events.

Focus group D - Ultimately what stops people is time and money. And so that's what I worry about, that fundamentally you can't change the two big things that stop people, and even if you create a website or people have created platforms before for people to feed in things like evaluation, you need to have the time to use those platforms.

Focus group B participant - It's not part of our job description if you like. You see something that sounds like an interesting report and you kind of mentally clock that I should read that, but it's really hard to keep reading through all the different reports unless you know it's actually specifically [of use]. It's not practitioners keeping up with the literature; it's the literature keeping up with the practitioners because actually practice has moved on far quicker than the research. 
Participants indicated that much of their learning was derived on the job, and through observing other people's practice. This was discussed in the Wellcome Trust Review of the U.K. Informal Learning Sector [Wellcome Trust, 2012], where science communication practitioners were described as 'craftspeople'. While practitioners were keen to learn from research, they also sought to gain recognition for their existing professionalism and tacit knowledge as a sector.

Inv4 - The way that we kind of get information from what other places are doing, is just by going to stuff ourselves. You know, it's having that experience of being an audience member and thinking about 'How does this feel?' or 'What's this space that I'm in here?'

Inv1 - The science communication profession fails to listen to people who've been doing it for years and years. So I think there's room for sharing of expertise and I think it's really important for people to be valued. And to be listened to, and to be seen as fellow professionals.

One practical suggestion made by many participants was for the development of a culture of reflective practice and peer review. Some participants felt that experienced practitioners should be encouraged to share their mistakes, as well as successes, with new entrants to the profession. This could take place at special meetings held alongside existing conferences or festivals, or through an online portal and practitioner website. An extension to this suggestion was for a system of peer review to be established, such as that found in the arts and theatre sectors.

Focus group D participant - One of my big things at the moment is trying to share learning between everybody; peer review, open and honest critical feedback, and try to use that to build everybody's skills.

Inv5 - It would be nice to have a community of ambitious practitioners who want to make excellent work and a way of connecting those practitioners and kind of allowing that community to be inspired by each other and to be peers and mentors for each other.

Whilst recognizing the professionalism and tacit knowledge of events practitioners, many participants still indicated that they were open to greater links with the academic or professional research communities. However, just as science communicators translate science for the public, participants indicated that science communication researchers should translate their research for the practitioner community. They discussed how research findings could be translated into language and recommendations which practitioners could practically use, without having to read the original source journal articles (which many could not access due to high journal fees). They also wanted to find ways to search for and be notified of this information in an easy and efficient manner.

Focus group B - Maybe all these things [research and academics] are not doing a big enough job about going to where practicing people are and remembering that the practicing people are all very busy people earning a living. Currently I would have to go in search of [the information]; they should be streaming them at me.

Inv8 - We value ourselves as communicators and I think that we don't necessarily practice what we preach enough, in terms of what we do either online or actually even in conferences. 
Co-creation of event research was raised as a possible suggestion to enable greater links between research and practice. Participants suggested that academic or professional researchers could be embedded into projects, or that event practitioners could be seconded to research departments to gain further qualifications.

Inv5 - As someone running a festival or as a practitioner, you're always going to gain from anyone doing any work with your audience or your festival. So it should create kind of mutually beneficial relationships between practice and research then, like obviously only if it is mutually beneficial, but that could be a really lovely way of getting well connected.

Focus group B participant - There's definitely some practitioners I think who would like to be able to combine a practice with research. If you find financial incentive for somebody to do the research whilst combining it with being a brilliant practitioner I think that would really help with the career professional development of science communication.

Participants were asked to indicate which areas of research would most benefit this nascent sector. These comments have been quantitatively summarized, as well as qualitatively illustrated with example quotes, in Table 4 . While many of the research areas discussed stimulated interest from the community, the overwhelming research preference $(N=22,40 \%)$ appeared to be for providing evidence for the long-term impact of live public science events.

Table 4. Participant preferences for future research on live science events.

\begin{tabular}{|c|c|c|}
\hline Research area & $\begin{array}{l}\text { Participants } \\
\text { who indicated } \\
\text { this was their } \\
\text { preferred future } \\
\text { research topic }\end{array}$ & Example quote \\
\hline Overall impact of events & $22(40 \%)$ & $\begin{array}{l}\text { "Longitudinal study of impact. What do they go away and } \\
\text { change as a result? It's the Holy Grail". }\end{array}$ \\
\hline $\begin{array}{l}\text { Audience characteristics } \\
\text { and preferences }\end{array}$ & $10(18 \%)$ & $\begin{array}{l}\text { "What would be the perspective of the people who live } \\
\text { through this? Looking at what the audience wants and how } \\
\text { the audience would prefer to engage". }\end{array}$ \\
\hline $\begin{array}{l}\text { Impact of setting and } \\
\text { format style }\end{array}$ & $9(16 \%)$ & $\begin{array}{l}\text { "I think impact of the setting and the format is a really in- } \\
\text { teresting area, as the nature of the venue changes the nature } \\
\text { of the conversation. You know that when you go into a lec- } \\
\text { ture hall you expect to be lectured at. And when you go into } \\
\text { a cafe you expect to have a conversation". }\end{array}$ \\
\hline $\begin{array}{l}\text { Impact of community } \\
\text { networks and collabor- } \\
\text { ators }\end{array}$ & $6(11 \%)$ & $\begin{array}{l}\text { "I have a particular interest in evaluation of cross discip- } \\
\text { linary projects, in particular, arts projects; I think there's a } \\
\text { real lack of evidence". }\end{array}$ \\
\hline $\begin{array}{l}\text { The potential for science } \\
\text { learning }\end{array}$ & $5(9 \%)$ & $\begin{array}{l}\text { "I'm sure that everybody would also love to know that what } \\
\text { we do makes a difference. So it would be great to know if } \\
\text { doing a hands-on demo produces more learning, or under- } \\
\text { standing, or inspiration, than just doing stuff with images } \\
\text { or a film. Is that true? Do we just assume that?" }\end{array}$ \\
\hline $\begin{array}{l}\text { Impact of regularity and } \\
\text { traditions in events }\end{array}$ & $3(5 \%)$ & $\begin{array}{l}\text { "I'm really interested in the qualitative differences that } \\
\text { come out through a university focusing on regular things } \\
\text { rather than a big festival once a year. Because I think both } \\
\text { are very valuable and do interesting things but they do dif- } \\
\text { ferent interesting things". }\end{array}$ \\
\hline
\end{tabular}


'Science Live' was a research project exploring practitioner perspectives on live science events, and this resulting article articulates the science events sector's aims and ethos in a research context. In total, 240 individuals contributed to the process: six project members, with extended teams based in Cambridge, U.K. and Cambridge, U.S.A.; the research framework was developed with input from 55 U.K. and 56 U.S.A. stakeholders; 90 practitioners were interviewed for the project; and 32 event producers offered ratification on the findings. The community overwhelmingly agreed that live science events constitute a distinct science communication sector which is not adequately described or researched in existing literature, and which they would like to see develop further as a profession.

Practitioners indicated that events are informal and creative, providing an inherently social engagement with science in its widest definition. They asserted that events happen in or with the public(s), where the primary mode of interaction is face-to-face, excluding online interactions as a primary format type. Despite agreeing on a definition, practitioners indicated that the creativity of the sector should always allow for different types of events, ranging from intimate storytelling to touring science shows with a digital component.

The project reached out to practitioners involved in live science event production who may not think of themselves primarily as science communicators, identifying instead as corporate events managers or community activists. Such practitioners are difficult to identify, and may not have resources or inclination to joining in-person sector-development meetings. A longer lead-time, greater resources, and strategic approach to involving such participants are needed if live science event research is to significantly diversify its participant base.

Many participants stated that connections to research are not a principal focus of their work, despite an abiding interest towards evidence-based development. Open access publication removes one barrier, but rather than digesting detailed evaluation methodologies and epistemological theories, practitioners are more interested in seeing examples of deployment and how this could fit with their own programs. Many discussed how research findings should be translated into formats - languages and recommendations - which practitioners would find meaningful.

There was a clear mandate for professional development of the live science event sector, even short-term evaluation of some form is common practice and there is a large appetite for networking, especially across and between event types. Future research and projects should explore options to develop the sector with dedicated associations and funded coordinators to promote and communicate with sector members. In particular, developing the professionalism of events and event producers within this sector should be supported by exploring options for greater connections between practitioners, and between practitioners and researchers, to enable co-production and action research.

Finally, the event practitioner community overwhelmingly supported research into the long-term impacts of live public science events, exploring the impacts for both audiences and those producing or presenting the events (including scientists). It is hoped that future research studies will address practitioner needs, in order to further develop public engagement with science. 
Archer, L., Dawson, E., DeWitt, J., Seakins, A. and Wong, B. (2015). "“Science capital": A conceptual, methodological, and empirical argument for extending bourdieusian notions of capital beyond the arts'. Journal of Research in Science Teaching 52 (7), pp. 922-948. https://doi.org/10.1002/tea.21227.

Bensaude Vincent, B. (2014). 'The politics of buzzwords at the interface of technoscience, market and society: The case of "public engagement in science"'. Public Understanding of Science 23 (3), pp. 238-253. https://doi.org/10.1177/0963662513515371.

Boyette, T. and Ramsey, J. (2019). 'Does the messenger matter? Studying the impacts of scientists and engineers interacting with public audiences at science festival events'. JCOM 18 (02), A02. https://doi .org/10.22323/2.18020202.

Braun, V. and Clarke, V. (2006). 'Using thematic analysis in psychology'. Qualitative Research in Psychology 3 (2), pp. 77-101. https://doi.org/10.1191/1478088706qp063oa.

British Science Association (2018). Science festival network members. URL: https : //ww w.britishscienceassociation .org/uk-science-festivals-network.

Bultitude, K. (2014). 'Science festivals: do they succeed in reaching beyond the 'already engage'?' JCOM 13 (04), C01. URL: http://jcom.sissa.it/archive/13/04/JCOM_1304_2014_C01.

Bultitude, K., McDonald, D. and Custead, S. (2011). 'The Rise and Rise of Science Festivals: an international review of organised events to celebrate science'. International Journal of Science Education, Part B 1 (2), pp. 165-188. https://doi.org/10.1080/21548455.2011.588851.

Crowell, A. and Schunn, C. (2014). 'Scientifically literate action: key barriers and facilitators across context and content'. Public Understanding of Science 23 (6), pp. 718-733. https://doi.org/10.1177/0963662512469780.

Daniel, M., Bogdan, G. and Daniel, Z. (2012). 'The use of event marketing management strategies'. Procedia - Social and Behavioral Sciences 46, pp. 5409-5413. https://doi.org/10.1016/j.sbspro.2012.06.448.

Dierking, L. D. (2008). 'Evidence and categories of ISE impacts'. In: Framework for evaluating impacts of informal science education projects. Ed. by

A. J. Friedman, pp. 19-30.

Dowell, E. (2014). 'Einstein's garden 2009-2014: unexpected encounters with science'. JCOM 13 (04), C06. https: //doi .org/10.22323/2.13040306.

Durant, J. (2012). 'The new wave of science festivals and their establishment'. Bulletin of the American Physical Society 57.

Durant, J., Buckley, N., Comerford, D., Fogg-Rogers, L., Fooshee, J., Lewenstein, B. and Wiehe, B. (2016). Science live: surveying the landscape of live public science events. Technical report. URL: https: //livescienceevents . files . wordpress . c om/2016/02/2016-science-live-landscape-survey.pdf.

Fikus, M. (2005). 'Audiences'. In: The white book: science communication events in Europe. European Science Communication Events Association, pp. 31-70.

Fogg-Rogers, L., Bay, J. L., Burgess, H. and Purdy, S. C. (2015). “'Knowledge is power": a mixed-methods study exploring adult audience preferences for engagement and learning formats over 3 years of a health science festival'. Science Communication 37 (4), pp. 419-451. https://doi.org/10.1177/1075547015585006.

Getz, D. (2010). 'The nature and scope of festival studies'. International Journal of Event Management Research 5, pp. 1-47. 
Getz, D. (2008). 'Event tourism: definition, evolution and research'. Tourism Management 29 (3), pp. 403-428.

https://doi.org/10.1016/j.tourman.2007.07.017.

Grand, A., Davies, G., Holliman, R. and Adams, A. (2015). 'Mapping public engagement with research in a UK University'. PLOS ONE 10 (4), e0121874, pp. 1-19. https://doi.org/10.1371/journal. pone.0121874. PMID: 25837803.

Jensen, E. and Buckley, N. (2011). The role of university student volunteers in festival-based public engagement. URL: https://www.publicengagement.ac.uk/si tes/default/files/Student\%20Volunteers\%20in\%20Festivals_0_0.pdf.

- (2014). 'Why people attend science festivals: interests, motivations and self-reported benefits of public engagement with research'. Public Understanding of Science 23 (5), pp. 557-573.

Kim, S. S., Choi, S., Agrusa, J., Wang, K.-C. and Kim, Y. (2010). 'The role of family decision makers in festival tourism'. International Journal of Hospitality Management 29 (2), pp. 308-318.

https://doi.org/10.1016/j.ijhm.2009.10.004.

Liu, X. (2009). 'Beyond science literacy: science and the public'. International Journal of Environmental \& Science Education 4, pp. 301-311.

Lloyd, R., Neilson, R., King, S. and Dyball, M. (2012). Review of Informal Science Learning. London, U.K.: Wellcome Trust.

Museums Libraries and Archives Council (2014). Active engagement with experience. URL: https://www . artscouncil .org.uk/measuring-outcomes/generic-learn ing-outcomes (visited on 4th February 2014).

Palmer, S. E. and Schibeci, R. A. (2012). 'What conceptions of science communication are espoused by science research funding bodies?' Public Understanding of Science 23 (5), pp. 511-527. https://doi.org/10.1177/0963662512455295.

Pontin, K. (2011). I'm a scientist evaluation report executive summary. URL: http://imascientist.org.uk/files/2011/02/Im-a-Scientist-evaluat ion-executive-summary-2010-2011.pdf.

Science Festival Alliance (2013). Key findings of independent evaluation.

Thomas, D. R. (2006). 'A general inductive approach for analyzing qualitative evaluation data'. American Journal of Evaluation 27 (2), pp. 237-246. https://doi.org/10.1177/1098214005283748.

Weihe, B. (2014). 'When science makes us who we are: known and speculative impacts of science festivals'. JCOM 13 (04), C02. URL: http://jcom. sissa. it/a rchive/13/04/JCOM_1304_2014_C01/JCOM_1304_2014_C02.

Wellcome Trust (2012). Analysing the U.K. science education community: the contribution of informal providers.

URL: https://wellcomelibrary . org/item/b21248023\#?c=0\&m=0\&s=0\&cv=0.

Authors

Laura Fogg-Rogers is a Senior Lecturer in STEM Education and Communication at UWE Bristol, U.K. E-mail: laura.foggrogers@uwe.ac.uk.

Ben Weihe is the Manager of the Science Festival Alliance in Massachusetts, U.S.A. E-mail: wiehe@mit.edu. 
Dane Comerford is the Festival Director at IF Oxford, U.K.

E-mail: danecomerford@gmail.com.

Julie Fooshee is a Communicator at the Science Festival Alliance in Massachusetts, U.S.A. E-mail: jay.fooshee@gmail.com.

John Durant is the Director of the Science Festival Alliance in Massachusetts, U.S.A. E-mail: jdurant@mit.edu.

Fogg-Rogers, L., Weihe, B., Comerford, D., Fooshee, J. and Durant, J. (2019).

'Science live - articulating the aims and ethos of science event practitioners in the U.S.A. and U.K.'. JCOM 18 (04), N01. https:/ / doi.org/10.22323/2.18040801. 